\title{
Clinical Guidance in Neuropalliative Care
}

\author{
An AAN Position Statement
}

Lynne P. Taylor, MD, Jessica M. Besbris, MD, William D. Graf, MD, Michael A. Rubin, MD, MA, Salvador Cruz-Flores, MD, MPh, and Leon G. Epstein, MD, on behalf of the Ethics, Law, and Humanities Committee, a joint committee of the American Academy of Neurology, American Neurological Association, and Child Neurology Society

Neurology ${ }^{\circledR}$ 2022;98:409-416. doi:10.1212/WNL.0000000000200063

In 1974, Dr. Balfour Mount introduced the term "palliative" from the Latin word palliare- "to wrap in comfort"-as a description of an approach that supports patients by focusing on improving their quality of life through symptom control, both physical and psychological, rather than on the diagnosis and treatment of their underlying disease. He sought to separate this part of supportive care from the emerging hospice movement, which was focused solely on the end of life. In the minds of many physicians as well as the lay public, palliative care is often seen as synonymous with hospice, and therefore leads to missed opportunities for the provision of palliative services earlier in the disease process.

In this position paper, we describe palliative care, which all neurologists give to their patients, and contrast it with specialty palliative care. We discuss essential elements of communication skills and prognostication and focus on ethical considerations in neuropalliative care as it relates to disorders of consciousness. In a 1996 position statement, the American Academy of Neurology (AAN) Ethics and Humanities Subcommittee declared that the provision of primary palliative care is the responsibility of all neurologists, and this position remains unchanged. ${ }^{1}$ Primary palliative care is provided by all clinicians who care for patients with serious illness, regardless of subspeciality. Since the publishing of that statement, the field of neuropalliative care has emerged into its own burgeoning subspecialty. ${ }^{2}$ In their 2018 textbook, Drs. Creutzfeldt and colleagues ${ }^{3}$ define neuropalliative care in this way: "We define a neuropalliative care approach as palliative care that focuses on the specific needs of patients with neurologic illness and their families. Neuropalliative care thus represents both an emerging subspecialty within neurology and palliative care, as well as a holistic approach to people suffering from neurologic illnesses." Recently, recognition of neuropalliative care in professional organizations has increased as well: the AAN Pain and Palliative Care Section split into 2 separate sections, a Neuropalliative Care Special Interest Group has formed at the American Academy of Hospice and Palliative Medicine, and a new International Neuropalliative Care Society has been established.

Given the remarkable growth of this field since our prior statement, this revision to the AAN's 1996 position statement updates ethical considerations in the new neuropalliative care landscape. This article also replaces 3 other AAN position papers regarding supportive care for patients with unique disorders of consciousness: persistent vegetative state, ${ }^{4}$ those who are irreversibly paralyzed but retain cognition, ${ }^{5}$ and those who lack decisional capacity. ${ }^{6}$

Palliative care is an approach to medical care that aims to improve quality of life for patients with life-altering illness and their families, through prevention and management of physical, psychosocial, and spiritual suffering. ${ }^{7}$ Whereas primary palliative care is provided by all clinicians, specialty palliative care is provided by interdisciplinary teams: physicians, nurse practitioners,

Correspondence

Dr. Taylor

Itaylor@uw.edu

From the Department of Neurology (L.P.T.), University of Washington, Seattle; Department of Supportive Care Medicine and Neurology (I.M.B.), Cedars-Sinai Medical Center, Los Angeles, CA; Department of Pediatrics (Division of Neurology) (W.D.G.), Connecticut Children's, University of Connecticut, Farmington; Department of Neurology (M.A.R.), University of Texas Southwestern Medical Center, Dallas; Department of Neurology (S.C.C.-F.), Texas Tech University Center, El Paso; and Department of Pediatrics and Neurology (L.G.E.), Northwestern University School of Medicine, Chicago, IL.

Go to Neurology.org/N for full disclosures. Funding information and disclosures deemed relevant by the authors, if any, are provided at the end of the article.

This statement was approved by the Ethics, Law, and Humanities Committee, a joint committee of the AAN, ANA, and CNS, on December 2, 2020. This statement was approved by the AAN on July 21, 2021; ANA on January 27, 2022; and CNS on August 16, 2021. 


\section{Glossary}

AAN = American Academy of Neurology; ALS = amyotrophic lateral sclerosis; LPHD = lawful physician-hastened death; NICU $=$ neonatal intensive care unit; PDRD $=$ Parkinson disease and related disorders .

nurses, social workers, chaplains, and others whose primary clinical focus is palliative medicine. Palliative care does not seek to hasten the end of life, but to help patients have the best quality of life for as long as possible, while recognizing the inevitability of death and providing comfort and dignity when the end of life arrives. Palliative care can be initiated early in the process of a life-limiting illness, across both inpatient and outpatient settings, concurrent with life-prolonging care, and continued with escalating intensity of interventions until the end of life. Studies of patients with advanced illness have even found a trend toward longer survival for patients receiving early palliative care intervention. ${ }^{8-11}$ Clinical decision-making in palliative care is no different than other shared medical decision-making, which includes an obligation to honor the ethical principles of autonomy, beneficence, and nonmaleficence. Hospice represents the transition from lifeprolonging care to comfort-focused end of life care; hospice represents only one facet of palliative medicine, and the two are not synonymous. Common misconceptions are that palliative care is a transition in care rather than the addition of a helpful service and the idea that palliative care should not be utilized "too early" in the course of a life-threatening illness.

\section{Palliative Care for Patients With Neurologic Disorders}

The field of palliative care initially developed as a care model for patients with advanced cancer; however, in recent years, evidence has demonstrated a benefit for palliative care in serious neurologic illnesses ${ }^{12,13}$ due to the high symptom burden, functional neurologic decline, high caregiver needs, prognostic uncertainty, and the need for complex decision-making throughout the course of illness. ${ }^{14}$ The neurologic patient will often transition from being the primary decision-maker at the beginning of the illness to requiring a surrogate decision-maker due to cognitive decline. The neurologist has an ethical imperative to apply the principles of palliative medicine for these patients and refer to specialty palliative care when appropriate..$^{15-18}$

Early palliative care consultation should be considered to maximize symptom management and to facilitate rapportbuilding and engagement in advance care planning and goals of care setting. Potential triggers for inpatient and outpatient palliative care consultation have been proposed but a standard of care is yet to be established. ${ }^{19,20}$

\section{Pediatric Neuropalliative Care}

Neuropalliative care decision-making during infancy, childhood, and adolescence poses challenges to physicians, parents, and guardians. The natural histories of severe neurodevelopmental disorders range from anencephaly, where postnatal survival is typically limited to a few hours or days, to a spectrum of other cerebral malformations, neurogenetic disorders, early-onset neurodegenerative diseases, and perinatal and postnatal brain injuries, in which longer life expectancies with secondary severe neurodevelopmental disabilities are anticipated.

Neonatal neuropalliative care deserves extra consideration as one-third of pediatric deaths occur in the neonatal period of life, most often in the neonatal intensive care unit (NICU) and after withdrawal of life-sustaining interventions. ${ }^{21} \mathrm{Di}$ agnosis can be made by prenatal imaging (e.g., ultrasonography or fetal MRI) and genetic testing (e.g., cell-free DNA, amniocentesis or chorionic villi sampling). Death may occur immediately, prior to, or shortly after birth and thus the integration of antenatal and perinatal neuropalliative care can be helpful to women continuing pregnancy despite severe fetal neurologic abnormalities. Antenatal neuropalliative care focuses on diagnostic information, family-centered communication, prognostication, shared decision-making, and pain and symptom management. ${ }^{22,23}$ Neonates with major malformations, syndromes, and suspected genetic disorders first recognized after birth are candidates for rapid genomic testing in the NICU. Such testing provides high diagnostic utility but creates new challenges for informed consent and parental decision-making. ${ }^{24}$ Pediatric neuropalliative care consultation benefits families striving to maximize the quality of their child's remaining life and allows them to declare their preferences regarding advanced directives for their child. Clinical practice guidance for pediatric palliative care includes strategies to enhance shared decision-making. ${ }^{25,26}$

In older children, the primary cause of death is usually progressive respiratory deterioration. Ethical dilemmas revolve around the need for escalating supportive care to sustain life, against invasive ventilation and technology dependency, in the presence of profound disability and worsening quality of life. End of life decision-making in pediatric neurologic disorders must consider the cognitive abilities of the child, the diagnosis, the perceived level of suffering, parental values, and the family's understanding of the prognosis.

Physician-hastened death in assenting adolescents with decisionmaking capacities is impermissible in the United States and most other countries and the importance of neuropalliative care should be recognized as a viable option for care.

\section{Communication}

Given the high prevalence of life-altering neurologic conditions, neurologists need training in serious illness communication. Necessary communication skills include delivering bad news, assessment, explaining prognosis, assisting patients and families in the process of decision-making, and setting limits 
when certain types of care are objectively futile. Many published educational resources and protocols are utilized in training programs and in clinical practice. ${ }^{27-31}$ The familiarity that neurologists have with these tough conversations supports the argument that all neurologists should attend to their patient's palliative needs and be able to recognize when the demands of the situation require assistance from palliative care specialists.

Discussions of prognosis are critical to facilitating disease understanding and empowering patients and surrogates in the decision-making process to achieve care consistent with established goals of care. Many neurologic illnesses such as stroke, postanoxic coma, traumatic brain injury, encephalitis, and demyelinating disease inherently involve unknown degrees of acute survival, functional recovery, or chance of recurrence. Neurologists often cite prognostic uncertainty as the reason they feel uncomfortable discussing decisionmaking with patients and families, but the literature supports that patients desire prognostic information even when prognosis is uncertain and appreciate when their physicians disclose the presence of that uncertainty. ${ }^{32-34}$

Furthermore, clinicians are at risk of overestimating prognosis (when they have a longstanding relationship with a patient $)^{35}$ or underestimating prognosis (when withdrawal bias is present) and must remember to use evidence-based estimates and explore personal biases when offering prognostic assessments. ${ }^{36}$ The statistical language clinicians use is easily misinterpreted by patients and their families. A study of decisionmakers in a critical care environment demonstrated that even college-educated people possessed low numeracy (the ability to understand numbers), which led to discordant surrogate prognostic estimates. ${ }^{37}$

There are established strategies for making decisions in the setting of prognostic uncertainty, including describing the best case/worst case scenario, and most likely functional outcomes, for a particular illness, and gauging the acceptability of each of these outcomes based on a patient's known wishes. ${ }^{38,39}$ It is also helpful to frame predictions of longevity in time intervals (hours to days, days to weeks, weeks to months, months to years, or many years), rather than more specific time frames, to enhance accuracy and flexibility.

Goals of care conversations should take place at routine intervals and triggered by sentinel events unique to each disease process. ${ }^{17}$ Addressing goals of care as routine may destigmatize conversations around the potential for worsening illness and help patients and families be more prepared to make decisions when clinical deterioration occurs.

It is critical that clinicians engage in a shared decision-making model with patients and families rather than placing the entire burden of decision-making on the affected parties. This approach requires the physician to elicit a patient's goals, make recommendations based on whether medical treatments are likely to achieve those goals, and work with patients and families to finalize a treatment plan.

In cases of lost cognitive capacity, it is important to honor patient autonomy by referring to advance care planning documents, if they exist, and guiding the surrogate decisionmakers in the use of substituted judgement to make decisions that they believe the patient would have made based on prior written or expressed wishes, or previously exhibited attitudes or behaviors, rather than choices solely in line with the family members' own preferences. ${ }^{40}$ The appropriate surrogate should be guiding decisions, whether designated by a durable power of attorney for health care or governed by state law.

When prognosis is uncertain, time-limited trials can be recommended to allow maximal recovery before further decisions are made. ${ }^{12}$ A prolonged period of aggressive lifeprolonging care should not be pursued, if the surrogate is confident that this type of care would not be in line with the patient's preferences, even if a degree of recovery is believed to be possible.

When treatments are physiologically futile (i.e., incapable of achieving a desired physiologic goal), it is the clinician's responsibility to remove the burden of decision-making entirely by explaining that such interventions will not be offered. ${ }^{41}$ It is counter to the principle of nonmaleficence to offer such treatments, as they may cause harm in the absence of potential benefit. Futility exists in the context of all medical specialties; a specific example in the setting of neurologic disease includes cardiopulmonary resuscitation in the setting of cardiac arrest due to irreversible herniation.

Not all patients and families may welcome discussions around serious illness. Resistance to these conversations can arise from a multitude of reasons, including cultural and language barriers, which make such communication challenging, or mistrust in the medical system. In general, when encountering hesitance from patients and families for serious illness communication, the clinician should explore the reasons for such resistance, demonstrate humility and an interest in individual cultural beliefs, and seek to meet patients and families where they are in order to facilitate ongoing discussions. When language barriers are present, multilingual family members should not be relied upon to translate serious illness conversations; formal interpreters should be invited to facilitate discussions. $^{42}$

Once communication has taken place, it is important to document care preferences as clearly as possible. This includes both clear documentation in the medical record, so that other providers with access to the chart are aware of care preferences, as well as durable medicolegal documentation to guide surrogates and emergency care providers in the setting of future lost capacity. The latter can be achieved by the completion of advance care planning documents. 
In assisting patients with the completion of these documents, the neurologist can help elicit broad preferences and focus documentation specifically on anticipated complications of a disease process. For this purpose, disease-specific advance directives have been developed for diseases such as dementia and amyotrophic lateral sclerosis (ALS), where certain decision points are predictable. Whereas disease course can sometimes be anticipated, consistency of patient preferences may not be predictable, as these may change over the course of illness. ${ }^{43}$ In a known phenomenon called the disability paradox, patients may perceive future states as being unacceptable, but may find these states acceptable once they become a reality, because of adaptability or shifting priorities during the disease course. For this reason, advance care planning and related documentation should be a dynamic process, revisited at intervals together by the patient and provider.

\section{Transitions to End-of-Life Care}

Physicians have strong ethical obligations to sustain life, when possible and desired by the patient. When neurologic prognosis is poor, however, these ethical obligations should be carefully evaluated in the context of balancing the benefits and burdens of medical interventions, relief of suffering, and respect for patient autonomy. When life-prolonging care is no longer available or desired by a patient or surrogates, the clinician has an obligation to shift the focus of care to preserving quality of life and comfort as much as possible at the end of life. Hospice is a service that provides comfort-focused medical care as well as logistical, psychosocial, and spiritual support to patients and families facing the end of life. This service, fully supported by Medicare, is reserved for those patients who are believed to be in the last 6 months of their life if their disease follows the expected course. It is appropriate for those who wish to forgo aggressive life-sustaining treatment and who prefer to stay in the location of their choice (e.g., home, care facility) rather than return to the hospital. For patients who have active symptoms that are too complex to treat in an outpatient setting, many hospice organizations provide free-standing inpatient care facilities or partner with hospitals to provide those services. Although patients cared for on hospice have a limited prognosis, hospice seeks to provide the best quality of life possible from the time of enrollment to the time of death and provides bereavement support to families.

Hospice referral guidelines suggest that a patient should be referred to hospice if the anticipated survival is 6 months or less, but this can be challenging to assess in patients with chronic progressive diseases such as dementia, Parkinson disease, or multiple sclerosis. This challenge has the potential to cause delayed referral to hospice and a missed opportunity for specialized care at the end of life. From an ethical standpoint, when the goals of care are in line with hospice services, a clinician can and should err on the side of hospice referral, recognizing that the hospice will reassess prognosis every few months, and will continue enrollment if the estimate of 6 months still appears accurate, or disenroll the patient if prognosis appears to be improving. Many hospice clinicians are not familiar with the nuances of end-of-life care for patients with neurologic conditions, so collaboration between the referring neurologist and the accepting hospice clinician is key. Any physician can serve as the hospice attending of record and neurologists should consider serving in that role for their patients if they are able.

\section{Ethical Considerations for Neuropalliative Care in Specific Neurologic Disorders}

\section{Disorders of Consciousness}

One of the defining characteristics of neuropalliative care is the consideration that is specific to the neurologic disease state. The possibility of misdiagnosis and inaccurate prognostication are significant matters of concern for disorders of consciousness - on the patient side, because of limitations in motor function, impaired cognition, and fluctuations in vigilance, as well as on the physician side, because of indeterminate neurologic assessments. ${ }^{44,45}$ When neurologic diagnosis and prognosis are uncertain, serial examinations are necessary to reevaluate levels of cognition, psychological state, decision-making capacity, and disease trajectory.

\section{Acute Neurologic Illness}

\section{Locked-In Syndrome}

Patients with locked-in syndrome have evidence of injury to the lower brain and brainstem with relative sparing of the cerebral cortex. It may be caused by acute conditions such as basilar artery occlusion or chronic conditions such as ALS. Locked-in-syndrome is a state of irreversible paralysis (quadriplegia), often with respiratory and vocal paralysis (aphonia), with some preserved consciousness and an ability to communicate with eye movements or blinking. Consciousness in such patients may range from a chronic minimally conscious state with inconsistent but discernible evidence of environmental awareness to fully intact cognition. Without careful examination, patients with locked-in syndrome but preserved consciousness may be mistaken as having a disorder of consciousness and are at risk for having their decisional capacity and autonomy ignored. These patients may need assistance from speech pathologists to identify techniques to enhance communication, such as careful "yes/no" questioning, communication boards, or advanced eye-gaze technology. ${ }^{46}$ Even when properly diagnosed, these patients are at risk for having their preferences overridden due to the effort and time required to elicit these preferences and are at risk for unrecognized pain and suffering due to inability to communicate their experiences.

\section{Stroke (Severe Acute Brain Injury)}

Depending on the size and location of a severe stroke, patients may experience an acute change in functional status, cognitive abilities, and communication, with variable degrees of recovery. Those experiencing an acute stroke will benefit from serial assessments of recovery, a best-case/worst-case 
prognostic framework, time-limited trials of 3 to 6 months when in line with goals of care, efforts to enhance communication ability, and support for surrogates when capacity is lost. Hope and personhood are 2 important themes for families of patients in the intensive care unit to use when faced with prognostic uncertainty. ${ }^{47}$ One study has shown that surrogates mistrust clinicians' prognostic estimates and that being as general as possible, providing a range of best and worst outcomes, improves communication and decision making about complex supportive care measures. ${ }^{48}$

A minority of patients with first stroke have completed advance care directives and formally designated a substitute decision-maker in case they are unable to communicate their own health care choices. Neurologists should encourage stroke patients with retained decision-making capacity to complete advance care planning given the risk of recurrent stroke and loss of capacity in the future. ${ }^{49}$

\section{Minimally Conscious State}

For patients in coma or an unresponsive wakefulness syndrome, the possibility of recovery depends on both the severity and cause of the condition. Patients with prolonged disorders of consciousness may have slight recovery over months to years, only to remain severely disabled in a minimally conscious state. Patients should be allowed adequate recovery time before prognostic estimates and health care decisions are made. Physicians have heightened obligations to these patients because of their profound disabilities, loss of decisional capacity, and the irreversible nature of decisions to de-escalate life-sustaining care. Physicians should make reasonable attempts to enhance the ability of patients with such severe disabilities to communicate their feelings, needs, and values. When patients lack capacity, it is imperative to rely on advance care planning documents (when available) and the substituted judgement of surrogate decision-makers to guide ongoing care in line with the patient's known treatment preferences. Because prognosis may become clear over a period of several months, a time-limited trial may be offered to clarify prognosis and allow further care planning. ${ }^{4}$

\section{Progressive Neurologic Diseases}

Integration of neuropalliative care will be different for patients and families hoping for neurologic recovery than for those patients anticipating functional declines. For patients diagnosed with such a disease, gradual loss of physical and cognitive function may be anticipated. For these patients, early advance care planning conversations are recommended shortly after the time of diagnosis and before cognitive capacity is lost.

\section{Neuro-oncology}

Patients diagnosed with low-grade and malignant brain tumors want prognostic information even though this can be difficult and unreliable with molecular markers changing histologic diagnoses and new therapies becoming available. Caregiver and psychosocial support are essential given the high rates of distress and burnout in caregivers of patients with primary CNS malignancies, compounded by frequent loss of language and cognitive abilities on the part of the patient, coupled with common cortical neglect syndromes that can lead to significant family conflict. ${ }^{50}$

Communication challenges include when to begin goals of care discussions, how to support patients and caregivers during decision making, and how to increase familiarity with potential behavioral and communication problems in the future. ${ }^{51}$

\section{Dementia}

Mild cognitive impairment and dementia are common problems in aging. Dementia progression gradually leads to a level of cognitive impairment wherein patients are unable to understand medical information and to make important health care decisions. Proper and timely diagnosis can help patients, and their families, prepare for the consequences of cognitive dysfunction and loss of autonomy while respecting their identified values. ${ }^{52,53}$ The recent AAN position statement on ethical considerations in dementia diagnosis and care goes into greater detail on communication and support principles for these patients. ${ }^{54}$

\section{ALS and Frontotemporal Degeneration}

For patients with disorders such as ALS and other progressive conditions, efforts should be made to elicit and document goals and treatment preferences prior to extreme weakness and aphonia. In the course of such planning, it is important to anticipate patient preferences for future disability-specific decisions (e.g., feeding tubes, mechanical ventilation). When patients are considering opting for these life-sustaining interventions, it is also important to identify the patient's minimal acceptable outcome. This is especially critical given that interventions such as tracheostomy and mechanical ventilation prolong life for patients with ALS despite disease progression, such that many of these patients may become locked-in and have difficulty expressing a desire to shift the focus of care in the future. ${ }^{55,56}$

There is increasing recognition of the prevalence of cognitive impairment and dementia for patients with ALS. Given the poor prognosis of patients with ALS-frontotemporal degeneration and their need for additional care and medical services, it is crucial to identify such patients at an early stage.

\section{Parkinson Disease and Related Disorders}

Parkinson disease and related disorders (PDRD) represents a challenging but important opportunity for primary and specialty palliative intervention. These diseases are marked by a protracted course of many years with slow decline in function, reduction in the efficacy of medications, accumulating burden of motor and nonmotor symptoms, and a high incidence of cognitive impairment and dementia. Several trials have demonstrated benefit for patients with PDRD receiving palliative care intervention. ${ }^{11}$ However, the appropriate timing of integration of specialty palliative care is not yet clear. As they 
will likely be the main source of symptom management and support for a number of years, primary neurologists must strive to anticipate and treat symptoms, recognize and address psychosocial and spiritual distress and caregiver burden, engage patients and families in advance care planning prior to the onset of cognitive impairment, and identify opportunities for specialty palliative care intervention on a case-by-case basis. ${ }^{57}$

\section{Additional Ethical Considerations in Neuropalliative Care}

\section{Refusal/Withdrawal of Treatment}

Patients with irreversible neurologic diseases and retained health care decision-making capacity may decide to refuse or discontinue life-sustaining interventions. These treatments may include artificial nutrition and hydration, mechanical ventilation, vasopressors and inotropes, or antibiotics. Under the ethical principle of respect for autonomy, competent patients have the right to refuse any imposed life-prolonging treatment to permit a natural and peaceful death to occur. Such an action is in accordance with the highest ethical standards of medical practice. In conscious patients diagnosed with progressive neurologic disease, physicians have ethical obligations to ascertain that a patient's decision to refuse treatment has been reached with full knowledge of the consequences, appropriate consideration of treatment alternatives, consistent perspectives over time, and the absence of impulsive or reactive decision-making. If a patient has lost capacity, a designated surrogate may make a fully informed decision to discontinue life-sustaining treatment on the patient's behalf. If a physician has a moral objection to carrying out the patient's or surrogate's decision to remove life-support systems, the physician should not be forced to act against his or her conscience. The physician is then obligated to transfer the care of the patient to another physician.

\section{Management of Severe Refractory Symptoms at End of Life}

Once a decision is made to forgo life-sustaining treatment, physicians have an ethical obligation to minimize subsequent suffering. This is particularly important for patients with severe motor dysfunction and intact cognition because the potential for suffering is high, as is the risk of underrecognizing symptoms. Most symptoms at the end of life can be managed without the need for sedation, but this is not always the case when symptoms are severe or rapidly escalating. When a choice must be made between comfort and alertness, the patient and family preferences on this matter should be considered.

In some cases, symptoms may be so severe as to require doses of medication that may result in unconsciousness (palliative sedation) or respiratory depression. Under the principle of double effect and proportionate reason, it is ethical to treat pain or suffering, as the primary intent of the treatment in this case is relief, not to hasten the end of the patient's life, even if the patient's death may be a foreseeable side effect of the treatment. ${ }^{58}$ Under such circumstances, physicians should be willing to administer adequate doses of medications such as opiates or benzodiazepines to reduce pain, dyspnea, anxiety, and other sources of acute discomfort in dying patients, even if these medications, as a secondary effect, contribute to respiratory depression, coma, or death (the principle of double effect). Conferring with specialist palliative care clinicians can be important for advice about appropriate titration and dosing strategies. Physicians (including hospice and palliative medicine clinicians) may not initiate or escalate morphine or other medications out of proportion to symptoms with the intention of speeding up the dying process. It is critical to provide education to patients and families on this point to assuage potential fears and in response to requests to hasten death in this manner.

\section{Lawful Physician-Hastened Death}

In recent years, several states have put into place laws allowing physician-hastened death. Patients receiving neuropalliative care may express an interest in lawful physician-hastened death (LPHD), but this issue is not exclusive to specialty palliative care, and requests for LPHD may be presented to any neurologist caring for adult patients with serious neurologic illnesses. An in-depth discussion of LPHD is beyond the scope of this article, but we refer the reader to the 2017 AAN position statement on the subject. ${ }^{59}$

\section{Education and Training}

There remains a gap in neurology training programs and we must advocate for more education in palliative care skills. A study of 49 neurology residency programs showed that lack of faculty expertise and time were the main barriers to providing palliative care education. A total of $42 \%$ of resident respondents reported being dissatisfied with their palliative care education and identified nonpain symptom management, pain assessment and management, and addressing spiritual distress as domains in which they felt least well trained. ${ }^{60}$ These data support increased palliative care education in neurology resident training programs. Formal assessment of communication skills during family meetings, use of standardized patients, and increased attention to pain and symptom management are a few strategies to supplement didactive lectures. A formal rotation on the palliative care consult service should also be encouraged, if available.

\section{Neuropalliative Care Clinical Research Questions}

Although the evidence base for neuropalliative care has been growing rapidly, there are a number of questions that must be answered in order to ensure optimal benefit for patients and clinicians. More work is needed to identify the best educational approaches to empower neurologists to practice effective primary palliative care, to establish models of inpatient and outpatient neuropalliative care that can be implemented broadly at medical centers, and to demonstrate the optimal timing of specialty neuropalliative care referral. ${ }^{17}$ Clinical decision-making aids should continue to be developed to help 
inform patients about disease states and help them with their decision-making process. Research is also needed to assess how and when advance care planning should be changed along the disease trajectory.

\section{Discussion}

Palliative care, developed from the hospice movement, has become an essential part of medical practice, long before the end of life has arrived. Whereas relieving suffering and providing clarity in goals of care take priority, the focus on comfort late in a disease course has expanded to comfort throughout a disease course and recognition of the need to anticipate upcoming medical decisions so they can be explored before the urgency of an immediate need has arrived.

From the 1996 article "Palliative care in neurology": "Many patients with neurologic diseases die after long illnesses during which a neurologist acts as the principal or consulting physician. Therefore, it is imperative that neurologists understand, and learn to apply, the principles of palliative medicine."

The clinical neurosciences have long since been separated as their own discipline, with unique challenges in diagnosis, treatment, prognosis, and coping. As the field of palliative care has developed, the uniqueness of neurologic disease is a natural fit for its own approach to palliative care. As the field of neuropalliative care evolves, we must make a concerted effort to not only recognize the obligation that all neurologic clinicians have to attend to palliative needs, but also learn to identify when challenging cases will benefit from the assistance of specialists in the field.

\section{Acknowledgment}

The following individuals participated in the development of this position statement as members of the Ethics, Law, and Humanities Committee, a joint committee of the AAN, American Neurological Association, and Child Neurology Society: Matthew Kirschen, MD, PhD, Vice Chair (Children's Hospital of Philadelphia); Katharina M. Busl, MD, MS (University of Florida); Winston Chiong, MD (University of California, San Francisco); Charles Flippen II, MD, FAAN (University of California, Los Angeles); Robin Conwit, MD, FAAN (NINDS/NIH); Julie Kurek, MD (Augusta University Medical Center); Daniel G. Larriviere, MD, JD, FAAN (Inova Neuroscience); Barney J. Stern, MD, FAAN (Johns Hopkins); Benjamin D. Tolchin, MD (Yale University); Amy Tsou, MD (ECRI Institute); Ericka P. Greene (Simpson), MD, FAAN (Methodist Hospital); and Ariane Lewis, MD (New York University). The authors thank Dr. Jessica Besbris (Cedars Sinai) and the members of the Section of Palliative Care, AAN, for their commentary.

\section{Study Funding}

The authors report no targeted funding.

\section{Disclosure}

L.P. Taylor, J. Besbris, W.D. Graf, and M.A. Rubin report no disclosures. S. Cruz-Flores reports participation on member adjudication committees for clinical trials for Novo Nordisk, Sunovion, and Galapagos (modest). L.G. Epstein reports no disclosures. Go to Neurology.org/N for full disclosures.

\section{Publication History}

Received by Neurology August 22, 2021. Accepted in final form January 3, 2022.

Appendix Authors

\begin{tabular}{lll}
\hline Name & Location & Contribution \\
\hline $\begin{array}{l}\text { Lynne P. } \\
\text { Taylor, MD }\end{array}$ & $\begin{array}{l}\text { Department of Neurology, } \\
\text { University of Washington, } \\
\text { Seattle }\end{array}$ & $\begin{array}{l}\text { Drafting/revision of the } \\
\text { manuscript for content, } \\
\text { including medical writing for } \\
\text { content; major role in the } \\
\text { acquisition of data; analysis } \\
\text { or interpretation }\end{array}$ \\
\end{tabular}

Jessica M. Department of Supportive Drafting/revision of the

Besbris, MD Care Medicine and manuscript for content, Neurology, Cedars-Sinai including medical writing for Medical Center, Los Angeles, content

CA

\begin{tabular}{|c|c|c|}
\hline $\begin{array}{l}\text { William D. } \\
\text { Graf, MD }\end{array}$ & $\begin{array}{l}\text { Department of Pediatrics } \\
\text { (Division of Neurology), } \\
\text { Connecticut Children's, } \\
\text { University of Connecticut, } \\
\text { Farmington }\end{array}$ & $\begin{array}{l}\text { Drafting/revision of the } \\
\text { manuscript for content, } \\
\text { including medical writing for } \\
\text { content }\end{array}$ \\
\hline $\begin{array}{l}\text { Michael A. } \\
\text { Rubin, MD, } \\
\text { MA }\end{array}$ & $\begin{array}{l}\text { Department of Neurology, } \\
\text { University of Texas } \\
\text { Southwestern Medical } \\
\text { Center, Dallas }\end{array}$ & $\begin{array}{l}\text { Drafting/revision of the } \\
\text { manuscript for content, } \\
\text { including medical writing for } \\
\text { content }\end{array}$ \\
\hline $\begin{array}{l}\text { Salvador } \\
\text { Cruz-Flores, } \\
\text { MD, MPh }\end{array}$ & $\begin{array}{l}\text { Department of Neurology, } \\
\text { Texas Tech University Center, } \\
\text { El Paso }\end{array}$ & $\begin{array}{l}\text { Drafting/revision of the } \\
\text { manuscript for content, } \\
\text { including medical writing for } \\
\text { content }\end{array}$ \\
\hline $\begin{array}{l}\text { Leon G. } \\
\text { Epstein, MD }\end{array}$ & $\begin{array}{l}\text { Department of Pediatrics and } \\
\text { Neurology, Northwestern } \\
\text { university School of } \\
\text { Medicine, Chicago, IL }\end{array}$ & $\begin{array}{l}\text { Drafting/revision of the } \\
\text { manuscript for content, } \\
\text { including medical writing for } \\
\text { content }\end{array}$ \\
\hline
\end{tabular}

\section{References}

1. Report of the Ethics and Humanities Subcommittee of the American Academy of Neurology. Palliative care in neurology. Neurology. 1996;46:870-872.

2. Robinson MT, Barrett KM. Emerging subspecialties in neurology: neuropalliative care. Neurology. 2014;82(21):e180-182.

3. Creutzfeldt CJ, Kluger BM, HollowayRG, eds. Neuropalliative Care: A Guide to Improving the Lives of Patients and Families Affected by Neurological Disease. Springer; 2019.

4. American Academy of Neurology. Position of the American Academy of Neurology on certain aspects of the care and management of the persistent vegetative state patient. Neurology. 1989;39:125-126.

5. American Academy of Neurology. Position of the American Academy of Neurology on certain aspects of the care and management of profoundly and irreversibly paralyzed patients with retained consciousness and cognition. Neurology. 1993;43: 222-223.

6. American Academy of Neurology. Position of the American Academy of Neurology on laws and regulations concerning life-sustaining treatment, including artificial nutrition and hydration, for patients lacking decision-making capacity. Neurology. 2007; 68(14):1097-1100.

7. World Health Organization. Palliative care. Accessed August 10, 2021. who.int/ cancer/palliative/definition/en/.

8. Temel JS, Greer JA, Muzikansky A, et al. Early palliative care for patients with metastatic non-small cell lung cancer. $N$ Engl J Med. 2010;363:733-742. 
9. Harrison KL, Kotwal AA, Smith AK. Palliative care for patients with noncancer illnesses. JAMA. 2020;324(14):1404-1405.

10. Quinn KL, Shurrab M, Gitau K, et al. Association of receipt of palliative care interventions with health care use, quality of life, and symptom burden among adults with chronic noncancer illness: a systematic review and meta-analysis. JAMA. 2020; 324(14):1439-1450

11. Kluger BM, Miyasaki J, Katz M, et al. Comparison of integrated outpatient palliative care with standard care in patients with Parkinson disease and related disorders: a randomized clinical trial. JAMA Neurol. 2020;77(5):551-560.

12. Holloway RG, Arnold RM, Creutzfeldt, et al. Palliative and end-of-life care in stroke: a statement for healthcare professionals from the American Heart Association/ American Stroke Association. Stroke. 20142014;45(6):1887-1916.

13. Veronese $S$, Gallo G, Valle A, et al. Specialist palliative care improves the quality of life in advanced neurodegenerative disorders: NE-PAL, a pilot randomised controlled study. BMJ Support Palliat Care. 2017;7(2):164-172.

14. Miyasaki JM, Long J, Mancini D, et al. Palliative care for advanced Parkinson disease: an interdisciplinary clinic and new scale, the ESAS-PD. Parkinsonism Relat Disord. 2012;18:S6-S9.

15. Tarolli CG, Holloway RG. Palliative care and Parkinson's disease: outpatient needs and models of care over the disease trajectory. Ann Palliat Med. 2020;9(suppl 1): S44-S51.

16. Oliver DJ, Borasio GD, Caraceni A, et al. A consensus review on the development of palliative care for patients with chronic and progressive neurological disease. Eur J Neurol. 2016;23(1):30-38.

17. Creutzfeldt CJ, Kluger B, Kelly AG, et al. Neuropalliative care: priorities to move the field forward. Neurology. 2018;91(5):217-226

18. Bar B, Creutzfeldt CJ, Rubin MA. Palliative care in the neuro-ICU: perceptions, practice patterns, and preferences of neurointensivists. Neurocrit Care. 2020;32(1): 302-305.

19. Chang RS, Poon WS. Triggers for referral to neurology palliative care service. Ann Palliat Med. 2018;7(3):289-295.

20. Creutzfeldt CJ, Wunsch H, Curtis JR, Hua M. Prevalence and outcomes of patients meeting palliative care consultation triggers in neurological intensive care units. Neurocrit Care. 2015;23(1):14-21

21. Fontana MS, Farrell C, Gauvin F, Lacroix J, Janvier A. Modes of death in pediatrics: differences in the ethical approach in neonatal and pediatric patients. J Pediatr. 2013; 162(6):1107-1111.

22. Kukora SK, Boss RD. Values-based shared decision-making in the antenatal period. Semin Fetal Neonatal Med. 2018;23(1):17-24.

23. Rent S, Bidegain M, Bost MH, Hornik C, Lemmon ME. Neuropalliative care for neonates. J Child Neurol. 2021;36(12):1120-1127.

24. Gyngell C, Newson AJ, Wilkinson D, Stark Z, Savulescu J. Rapid challenges: ethics and genomic neonatal intensive care. Pediatrics. 2019;143(suppl 1):S14-S21.

25. Liberman DB, Song E, Radbill LM, Pham PK, Derrington SF. Early introduction of palliative care and advanced care planning for children with complex chronic medical conditions: a pilot study. Child Care Health Dev. 2016;42:439-449.

26. Santoro JD, Bennett M. Ethics of end of life decisions in pediatrics: a narrative review of the roles of caregivers, shared decision-making, and patient centered values. Behav Sci. 2018;8:42

27. Baile WF, Buckman R, Lenzi R, Glober G, Beale EA, Kudelka AP. SPIKES: a six-step protocol for delivering bad news: application to the patient with cancer. Oncologist. 2000;5(4):302-311.

28. Brizzi K, Creutzfeldt CJ. Neuropalliative care: a practical guide for the neurologist. Semin Neurol. 2018;38(5):569-575.

29. EPEC: education in palliative and end-of-life care. Neurology curriculum. Accessed October 29, 2021. inpcs.org/i4a/pages/index.cfm?pageid=3324

30. Vital talk. Accessed October 29, 2021. vitaltalk.org/.

31. Center to Advance Palliative Care. Communication Skills. Accessed October 29, 2021. capc.org/training/communication-skills/.

32. Evans LR, Boyd EA, Malvar G, et al. Surrogate decision-makers' perspectives on discussing prognosis in the face of uncertainty. Am J Respir Crit Care Med. 2009; 179(1):48-53.

33. Quinn T, Moskowitz J, Khan MW, et al. What families need and physicians deliver: contrasting communication preferences between surrogate decision-makers and physicians during outcome prognostication in critically ill TBI patients. Neurocrit Care. 2017;27:154-162.

34. Ahalt C, Walter LC, Yourman L, et al. "Knowing is better": preferences of diverse older adults for discussing prognosis. J Gen Intern Med. 2012;27:568-575.
35. Christakis NA, Lamont EB. Extent and determinants of error in doctors' prognoses in terminally ill patients: prospective cohort study. BMJ. 2000;320(7233):469-472.

36. Holloway RG, Gramling R, Kelly AG. Estimating and communicating prognosis in advanced neurologic disease. Neurology. 2013;80(8):764-772.

37. Leiter N, Motta M, Reed R, et al. Numeracy and interpretation of prognostic estimates in intracerebral hemorrhage among surrogate decision makers in the neurologic ICU. Crit Care Med. 2018;46:264-271.

38. Siegel C, Besbris J. Shared decision-making in the setting of a large ischemic stroke. In Palliative Skills for Frontline Physicians. Springer Publishing; 2020.

39. Taylor LJ, Nabozny MJ, Stafffens NM, et al. A framework to improve surgeon communication in high-stakes surgical decisions: best case/worst case. JAMA Surg. 2017;152(6):531-538.

40. Cai X, Robinson J, Muehlschlegel S, et al. Patient preferences and surrogate decision making in neuroscience intensive care units. Neurocrit Care. 2015;23(1):131-141.

41. Bosslet GT, Pope TM, Rubenfeld GD, et al; American Thoracic Society ad hoc committee on futile and potentially inappropriate treatment; American Thoracic Society; American Association for Critical Care Nurses; American College of Ches Physicians; European Society for Intensive Care Medicine; Society of Critical Care. An official ATS/AACN/ACCP/ESICM/SCCM policy statement: responding to requests for potentially inappropriate treatments in intensive care units. Am J Respi Crit Care Med. 2015;191(11):1318-1330.

42. Norris WM, Wenrich MD, Nielsen EL, Trece PD, Carey Jackson J, Randall Curtis J. Communication about end-of-life care between language-discordant patients and clinicians: insights from medical interpreters. J Palliat Med. 2005;8:1016-1024.

43. Sokol LL, Young MJ, Paparian J, et al. Advance care planning in Parkinson's disease: ethical challenges and future directions. NPJ Parkinsons Dis. 2019;5:24.

44. Fins JJ, Bernat JL. Ethical, palliative, and policy considerations in disorders of con sciousness. Neurology. 2018;91(10):471-475

45. Giacino JT, Katz DI, Schiff ND, et al. Practice guideline update recommendations summary: disorders of consciousness: report of the guideline development, dissemination, and implementation subcommittee of the American Academy of Neurology; the American Congress of Rehabilitation Medicine; and the National Institute on Disability, Independent Living, and Rehabilitation Research. Neurology. 2018;91(10) 450-460.

46. Linse K, Aust E, Joos M, Hermann A. Communication matters: pitfalls and promise of high-tech communication devices in palliative care of severely physically disabled patients with amyotrophic lateral sclerosis. Front Neurol. 2018;9603:1-18.

47. Schutz REC, Coats HL, Engelberg RA, et al. Is there hope? Is she there? How families and clinicians experience severe acute brain injury. J Palliat Med. 2017;2:170-176.

48. Hwang DY, Knies AK, Mampre D, et al. Concerns of surrogate decision makers for patients with acute brain injury: a US population survey. Neurology. 2020;94 e2054-e2068

49. Johnson PD, Ulrich A, Siv J, et al. Planning after stroke survival: advance care planning in the stroke clinic. J Am Heart Assoc. 2019;8:e011317.

50. Kluger BM, Ney DE, Bagley SJ, et al. Top ten tips palliative care clinicians should know when caring for patients with brain cancer. J Palliat Med. 2020;23(3):415-421.

51. Zehm A, Hazeltine AM, Greer JA, et al. Neurology clinicians' views on palliative care communication: how do you frame this? Neurol Clin Pract. 2020;106:527-534.

52. Poppe M, Burleigh S, Banerjee S. Qualitative evaluation of advanced care planning in early dementia (ACP-ED). PLoS One. 2013;8(4):e60412.

53. Smebye KL, Kirkevold M, Engedal K. Ethical dilemmas concerning autonomy when persons with dementia wish to live at home: a qualitative, hermeneutic study. BMC Health Serv Res. 2016;16:21.

54. Chiong W, Tsou AY, Simmons Z, et al. Ethical considerations in dementia diagnosis and care: AAN position statement. Neurology. 2021;97(2):80-89.

55. Mitsumoto H, Rabkin JG. Palliative care for patients with amyotrophic lateral sclerosis: "prepare for the worst and hope for the best." JAMA. 2007;298(2):207-216

56. Everett EA, Pedowitz E, Maiser S, et al. Top ten tips palliative care clinicians should know about amyotrophic lateral sclerosis. J Palliat Med. 2020;23(6):842-847.

57. Lum HD, Jordan SR, Brungardt A, et al. Framing advance care planning in Parkinson disease: patient and care partner perspectives. Neurology. 2019;92(22):e2571-e2579.

58. Knochler NJ. The principle of double effect and proportionate reason. Virtual Mentor. 2007;9(5):369-374.

59. Russell JA, Epstein LG, Bonnie RJ, et al. AAN position statement: lawful physicianhastened death. Neurology. 2018;90:420-422.

60. Mehta AK, Najar S, May N, et al. A needs assessment of palliative care education among United States adult neurology residency programs. J Palliat Med. 2018;21(10) $1448-1457$ 


\section{Neurology}

\section{Clinical Guidance in Neuropalliative Care: An AAN Position Statement}

Lynne P. Taylor, Jessica M. Besbris, William D. Graf, et al.

Neurology 2022;98;409-416

DOI 10.1212/WNL.0000000000200063

This information is current as of March 7, 2022

\section{Updated Information \&} Services

\section{References}

Citations

Subspecialty Collections

\section{Permissions \& Licensing}

Reprints including high resolution figures, can be found at: http://n.neurology.org/content/98/10/409.full

This article cites 54 articles, 15 of which you can access for free at: http://n.neurology.org/content/98/10/409.full\#ref-list-1

This article has been cited by 2 HighWire-hosted articles: http://n.neurology.org/content/98/10/409.full\#\#otherarticles

This article, along with others on similar topics, appears in the following collection(s):

All Ethics in Neurology/Legal issues

http://n.neurology.org/cgi/collection/all_ethics_in_neurology_legal_iss ues

\section{Palliative care}

http://n.neurology.org/cgi/collection/palliative_care

Professional conduct and ethics

http://n.neurology.org/cgi/collection/professional_conduct_and_ethics Quality of life

http://n.neurology.org/cgi/collection/quality_of_life

Information about reproducing this article in parts (figures,tables) or in its entirety can be found online at:

http://www.neurology.org/about/about_the_journal\#permissions

Information about ordering reprints can be found online:

http://n.neurology.org/subscribers/advertise

Neurology ${ }^{\circledR}$ is the official journal of the American Academy of Neurology. Published continuously since 1951, it is now a weekly with 48 issues per year. Copyright @ 2022 American Academy of Neurology. All rights reserved. Print ISSN: 0028-3878. Online ISSN: 1526-632X.

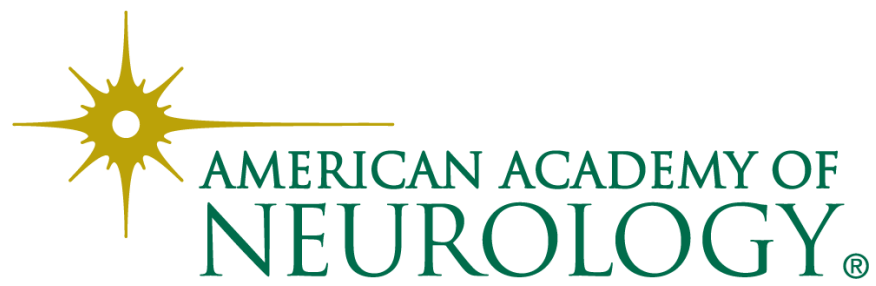

